\title{
Ferroelectric ceramic materials of the Aurivillius family
}

\author{
A. Peláiz-Barranco* and Y. González-Abreu \\ Facultad de Física \\ Universidad de La Habana. San Lázaro y L \\ Vedado. La Habana 10400, Cuba \\ *pelaiz@fisica.uh.cu
}

Received 17 July 2013; Revised 28 August 2013; Accepted 4 September 2013; Published 10 October 2013

\begin{abstract}
Ferroelectric ceramics are important materials with a wide range of industrial and commercial applications. Since the discovery of the phenomenon of ferroelectricity, they have been the heart and soul of several multibillion dollar industries, ranging from highdielectric-permittivity capacitors to developments in piezoelectric transducers, pyroelectric sensors, medical diagnostic transducers, electro-optical devices, etc. Materials based on barium titanate and lead zirconate titanate have dominated the field throughout their history. Actually, the ferroelectric ceramics from the Aurivillius family receive great attention due to their large remanent polarization, lead-free nature, relatively low processing temperatures, high Curie temperatures and excellent piezoelectric properties, which made them good candidates for multiple applications. This review presents a general overview of the progress in the studies on the ferroelectric ceramics from the Aurivillius family. The progress includes several aspects: (i) structural studies, (ii) dielectric and electric behavior, (iii) piezoelectricity, and (iv) pyroelectricity.
\end{abstract}

Keywords: Layered perovskites; dielectric relaxation; relaxors; dielectric permittivity.

\section{Introduction}

The Aurivillius family compounds are layered bismuth $\left[\mathrm{Bi}_{2} \mathrm{O}_{2}\right]^{2+}\left[\mathrm{A}_{n-1} \mathrm{~B}_{n} \mathrm{O}_{3 n+1}\right]^{2-}$, where sites $\mathrm{A}$ and $\mathrm{B}$ can be occupied for different elements. ${ }^{1}$ These are formed by the regular stacking of $\mathrm{Bi}_{2} \mathrm{O}_{2}$ slabs and perovskite-like blocks $\mathrm{A}_{n-1} \mathrm{~B}_{n} \mathrm{O}_{3 n+1}$ (Fig. 1). Various $\mathrm{A}$ and $\mathrm{B}$ cations are allowed, so that this family could have numerous representatives. Examples include $\mathrm{Bi}_{2} \mathrm{WO}_{6}(n=1), \mathrm{SrBi}_{2} \mathrm{Ta}_{2} \mathrm{O}_{9}(n=2)$ and $\mathrm{Bi}_{4} \mathrm{Ti}_{3} \mathrm{O}_{12}(n=3)$. Additional members can be generated by allowing the stacking of perovskite-like blocks of different sizes.

These materials have received great attention due to their large remanent polarization, lead-free nature, relatively low processing temperatures, high Curie temperatures and excellent piezoelectric properties, which make them good candidates for high-temperature piezoelectric applications and memory storage. ${ }^{2-12} \mathrm{~A}$ characteristic behavior of materials from this family is that some of them allow cation site mixing among atoms positions, especially between the bismuth and the A-site of the perovskite block. ${ }^{7,12}$ The ferroelectricity is strongly dependent on the crystallographic orientation of these materials, being the aim of continuing research. $^{4,5}$ It is well known that these have the majority polarization vector along the $a$-axis in a unit cell and that the oxygen vacancies prefer to stay in the $\mathrm{Bi}_{2} \mathrm{O}_{2}$ layers, where their effect upon the polarization is thought to be small, and not in the octahedral site that controls polarization. A considerable number of compositions exhibit a relaxor ferroelectric behavior. ${ }^{7}$ The origin of the relaxor behavior for these materials have been associated to a positional disorder of cations on A- or B-sites of the perovskite blocks that delay the evolution of long-rage polar ordering. ${ }^{2}$

The objective of this paper is to present a general overview of the principal analysis concerning the structural, dielectric, piezoelectric and pyroelectric studies, which have been carried out on ferroelectric ceramics from the Aurivillius family. Results are given from the literature, as well as from the work of the present authors.

\section{Structural Studies}

There are many reports concerning structural analysis in Aurivillius ferroelectric materials, which showed a more complicated structure than that of other ferroelectrics materials. In the first study, B. Aurivillius ${ }^{13}$ noted an orthorhombic distortion in these materials and described the structure with the Fmmm space group. Later, Newnham et al. proposed a most specific space group, $\mathrm{A} 2{ }_{1} \mathrm{am} .{ }^{13}$ Wachsmuth et al. reported a study, by using EXAFS spectroscopy and $\mathrm{X}$-ray diffraction, in a bilayer system $\mathrm{Ba}_{x} \mathrm{Sr}_{1-x} \mathrm{Bi}_{2} \mathrm{Nb}_{2} \mathrm{O}_{9}$, where the lattice parameters, $a$ and $c$, of the tetragonal phase, increase with increasing barium content and also the $\mathrm{Ba}^{2+}$ and $\mathrm{Sr}^{2+}$ ions substitute each other in the solid solution. They have suggested that the difference in the ionic radii provides a tilting and distortion of the surrounding $\mathrm{NbO}_{6}$ octahedra. ${ }^{9}$

Figure 2 shows the $\mathrm{X}$-ray diffraction pattern, at room temperature, for the $\mathrm{Sr}_{0.5} \mathrm{Ba}_{0.5} \mathrm{Bi}_{2} \mathrm{Nb}_{2} \mathrm{O}_{9}$ ferroelectric ceramic $(n=2)$, which was characterized by the authors. A pure 


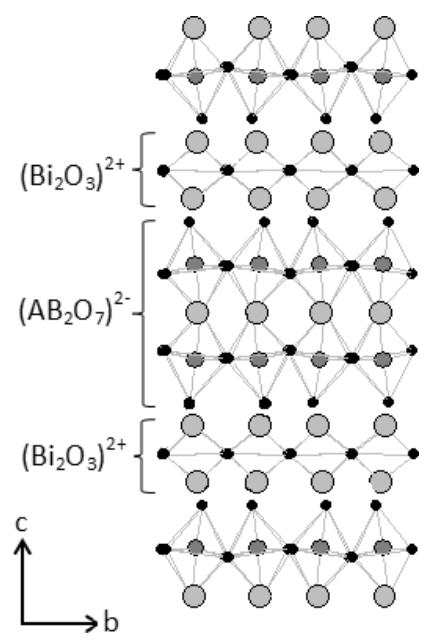

(a)

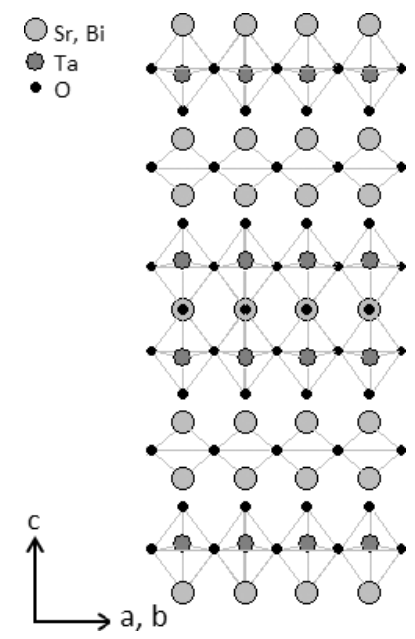

(b)
Fig. 1. Crystal structure of the $\mathrm{SrBi}_{2} \mathrm{Ta}_{2} \mathrm{O}_{9}$ system: (a) space group $\mathrm{A} 2{ }_{1} \mathrm{am}$, along the [100] direction, for temperatures below the transition temperature $\left(T_{c}\right)$; and (b) space group I4/mmm, along [110] direction, for temperatures much higher above $T_{c}$. For temperatures just above $T_{c}$, the space group is Amam.

orthorhombic structure with space group $\mathrm{A} 2_{1}$ am was evaluated, which is in agreement with previous reports for bilayer materials. ${ }^{7,11,13-15}$ The strongest diffraction peaks (115) follow the typical form $\left(\begin{array}{lll}1 & 1 & 2 n+1\end{array}\right)$, which corresponds to the highest diffraction peaks in Aurivillius materials, being $n$ the number of octahedral layers in the perovskite slab. ${ }^{16}$ The structural parameters were $a=5.5357 \pm 0.0004 \AA, \quad b=$ $5.5328 \pm 0.0005 \AA$ and $c=25.4057 \pm 0.0010 \AA$, which have suggested an increase in the cell volume related to the pure system $\mathrm{SrBi}_{2} \mathrm{Nb}_{2} \mathrm{O}_{9} \cdot{ }^{11,13}$ The results can be analyzed considering the incorporation of a bigger ion, barium, to the structure. ${ }^{17}$

Ismunandar et al. have published a Rietveld analysis of powder neutron diffraction data in the $\mathrm{SrBi}_{2} \mathrm{Nb}_{2} \mathrm{O}_{9}$ and

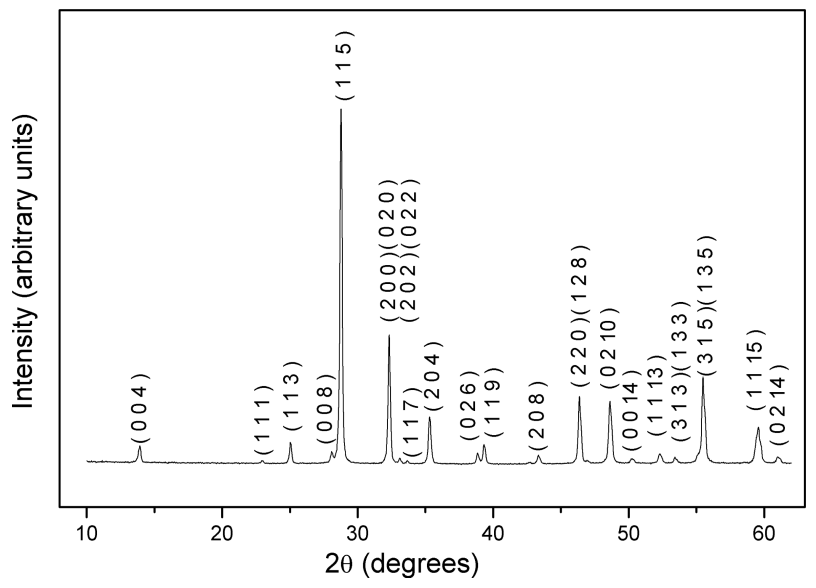

Fig. 2. X-Ray diffraction pattern, at room temperature, for the $\mathrm{Sr}_{0.5} \mathrm{Ba}_{0.5} \mathrm{Bi}_{2} \mathrm{Nb}_{2} \mathrm{O}_{9}$ ferroelectric ceramic.
$\mathrm{BaBi}_{2} \mathrm{Nb}_{2} \mathrm{O}_{9}$ systems. ${ }^{13}$ Both systems were reported as isostructurals with and orthorhombic space group ( $\left.\mathrm{A} 2_{\mathrm{i}} \mathrm{am}\right)$. The $\mathrm{SrBi}_{2} \mathrm{Nb}_{2} \mathrm{O}_{9}$ showed a larger distortion than that of the $\mathrm{BaBi}_{2} \mathrm{Nb}_{2} \mathrm{O}_{9}$ system. A second study was reported some years later ${ }^{11}$ in the same systems, showing a tetragonal structure for the $\mathrm{BaBi}_{2} \mathrm{Nb}_{2} \mathrm{O}_{9}$ material (space group $\mathrm{I} / \mathrm{mmm}$ ). The analysis also revealed that both $\mathrm{Ba}^{2+}$ and $\mathrm{Sr}^{2+}$ can also occupy the $\mathrm{Bi}^{3+}$ sites into the $\left(\mathrm{Bi}_{2} \mathrm{O}_{2}\right)^{2+}$ layers. ${ }^{11}$ Concerning the last result, other authors have pointed out that the sites mixing occurs to equilibrate the lattice dimensions between the $\left(\mathrm{Bi}_{2} \mathrm{O}_{2}\right)^{2+}$ layers and the perovskite blocks because of the $\left(\mathrm{Bi}_{2} \mathrm{O}_{2}\right)^{2+}$ layers constrain the perovskite blocks. $^{6,18}$

The structural behavior considering the incorporation of different cations to the A sites of the perovskite block has been also studied for $n=2$ and $n=3$. The bilayer system $\mathrm{ABi}_{2} \mathrm{Nb}_{2} \mathrm{O}_{9}$, with $\mathrm{A}=\mathrm{Sr}^{2+}, \mathrm{Ca}^{2+}$ and $\mathrm{Ba}^{2+}$, was refined using a combination of $\mathrm{x}$-ray and neutron powder diffraction data. ${ }^{7}$ The orthorhombic distortion of the unit cell increased as the A-site cation size decreased. The system $\mathrm{BaBi}_{2} \mathrm{Nb}_{2} \mathrm{O}_{9}$ showed a tetragonal structure with space group I $4 / \mathrm{mmm}$, and the systems with $\mathrm{Sr}^{2+}$ and $\mathrm{Ca}^{2+}$ showed an orthorhombic structure with space group $\mathrm{A} 2{ }_{1} \mathrm{am}^{7}$ All systems exhibited disordering between the A-site and the bismuth site in the $\left(\mathrm{Bi}_{2} \mathrm{O}_{2}\right)^{2+}$ layers, which increased with the ionic radii. ${ }^{7}$ The structural refinements of the three layers of Aurivillius ceramics, $\mathrm{Sr}_{2-x} \mathrm{~A}_{x} \mathrm{Bi}_{2} \mathrm{Nb}_{2} \mathrm{TiO}_{12}\left(\mathrm{~A}=\mathrm{Ca}^{2+}, \mathrm{Ba}^{2+}\right)$, have been also carried out by using $\mathrm{X}$-ray and neutron powder diffraction. ${ }^{18}$ It showed the preference of the $\mathrm{Ca}^{2+}$ ions to remain in the A site while the $\mathrm{Ba}^{2+}$ ions prefer the $\mathrm{Bi}$ sites.

Another analysis considering different number of perovskite blocks has been carried out for $\mathrm{Bi}_{2.5} \mathrm{Nan}_{1.5} \mathrm{Nb}_{n} \mathrm{O}_{3 n+3}$ ceramic systems, where $n$ takes values between 2 and $4 .{ }^{14}$ The systems with $n=2$ and $n=4$ showed an orthorhombic distortion with space group $\mathrm{A} 2{ }_{1} \mathrm{am}$; the system with $n=3$ showed an orthorhombic distortion with space group B2cb.

We could not forget in this section the $\mathrm{Bi}_{4} \mathrm{Ti}_{3} \mathrm{O}_{12}$ system, which is one of the most studied materials from the Aurivillius family because of its potential characteristics for capacitive memories applications. ${ }^{18-20}$ Some X-ray refinements on this material have shown a monoclinic space group B1a1; a monoclinic structure and the polarization direction in the ac plane, indicating a broken orthorhombic symmetry have been reported. ${ }^{19}$ On the other hand, it has been very interesting to study the structural analyses, which have been carried out considering a change in temperature. Many of the studied materials have reported an orthorhombic structure with space group $\mathrm{A} 2{ }_{1}$ am for low temperatures and a tetragonal structure with space group $\mathrm{I} 4 / \mathrm{mmm}$ for high temperatures. ${ }^{20}$ A Rietveld refinement of powder neutron diffraction data in $\mathrm{Sr}_{0.85} \mathrm{Bi}_{2.1} \mathrm{Ta}_{2} \mathrm{O}_{9}$ has shown an orthorhombic structure with space group A2 ${ }_{1}$ am below $648 \mathrm{~K}$, an orthorhombic structure with space group Amam for temperatures between 648 and $823 \mathrm{~K}$, and a tetragonal structure with space group I $4 / \mathrm{mmm}$ for temperatures above $823 \mathrm{~K}$ like in the other Aurivillius 
materials. The analysis has been also carried out in fourlayers of Aurivillius $\mathrm{SrBi}_{4} \mathrm{Ti}_{4} \mathrm{O}_{15} \cdot{ }^{15}$ For temperatures below $823 \mathrm{~K}$, an orthorhombic structure with space group $\mathrm{A} 2{ }_{1}$ am was reported, in the region between 823 and $933 \mathrm{~K}$ the raw diffraction data showed an orthorhombic space group Amam, which changes to the centrosymmetric tetragonal space group I4/mmm above $933 \mathrm{~K}$.

It has been also reported that the grain shape of the Aurivillius phase ferroelectric is different in nano- and micrometer scales. $^{21}$ The grain morphology has been studied for the $\mathrm{Bi}_{3.15} \mathrm{Nd}_{0.85} \mathrm{Ti}_{3} \mathrm{O}_{12}$ system considering ultrafine powders and bulk ceramics. ${ }^{21}$ The ultrafine powders with high purity were prepared by an hydrolysis method and the bulk ceramics were sintered at different temperatures $(1023 \mathrm{~K}, 1123 \mathrm{~K}$ and $1273 \mathrm{~K})$. The nanoparticles, which were obtained by the hydrolysis way, showed equiaxed shapes and formed agglomerates. The bulk ceramic sample, which was sintered at $1023 \mathrm{~K}$, preserved the nanoparticles and their agglomerates. The sintered sample at $1123 \mathrm{~K}$ showed a limited grain growth; the initial agglomerates disappeared to form large equiaxed grains. The ceramic sample, which was sintered at $1273 \mathrm{~K}$, showed an anisotropic grain growth with faceted platelet grains $(2011 \pm 30 \mathrm{~nm}$ of length and $307 \pm 30 \mathrm{~nm}$ of thickness).

\section{Dielectric and Electric Behavior}

Several analysis have been made concerning the relaxor behavior in $\mathrm{Sr}_{0.5} \mathrm{Ba}_{0.5} \mathrm{Bi}_{2} \mathrm{Nb}_{2} \mathrm{O}_{9}$ ceramics. ${ }^{2,6,22}$ Its origin has been associated to a positional disorder of cations on $\mathrm{A}$ or $\mathrm{B}$ sites of the perovskites, which delay the evolution of longrage polar ordering. It has been reported that the incorporation of barium to the $\mathrm{SrBi}_{2} \mathrm{Nb}_{2} \mathrm{O}_{9}$ system provides a higher frequency dependence of the dielectric parameters showing a relaxor-like ferroelectric. This behavior could be explained by considering the incorporation of a bigger ion into the $\mathrm{A}$ site of the perovskite block. The barium ions not only substitute the strontium ions in the A site perovskite block but enter the $\left(\mathrm{Bi}_{2} \mathrm{O}_{2}\right)^{2+}$ layers leading to an inhomogeneous distribution of barium and local charge imbalance in the layered structure.

Barium and titanium modified bismuth titanate materials have been reported as a new example of barium-bearing Aurivillius type ferroelectric relaxors. ${ }^{23}$ The onset of the relaxor behavior was correlated to the relaxation of polar clusters induced by the heterovalent substitution on $\mathrm{Bi}^{3+}$ and $\mathrm{Ti}^{4+}$ sites.

Studies of the dielectric spectra at high frequencies for several compounds of the Aurivillius family have shown that the low-frequency dielectric anomalies near and above ferroelectric phase transitions cannot be explained just by softening of polar phonons, as expected for classical displacive ferroelectrics. $^{20}$ The lowest frequency phonon softens on heating only partially with no anomaly near the Curie point. The authors have suggested the presence of polar clusters in the paraelectric phase, whose dynamics should be in origin of the relaxations.

Niobium doping of $\mathrm{Bi}_{3} \mathrm{NbTiO}_{9}$ was found to increase the dielectric permittivity due to the effect of bismuth vacancies produced by donor doping with $\mathrm{Nb}^{4+}$ on the B-site. ${ }^{24}$ With increasing sintering temperature, the dielectric parameter decreased due to a decrease in the extrinsic contribution from domain wall movement. Based on the high-temperature dc conductivity, the band gap was determined to be $3.4 \pm 0.2 \mathrm{eV}$.

The layered structure of $\mathrm{K}_{0.5} \mathrm{La}_{0.5} \mathrm{Bi}_{2} \mathrm{Ta}_{2} \mathrm{O}_{9}$ has shown a broad dielectric anomaly with frequency dependence at maximum temperature. ${ }^{25}$ The results were fitted by using Vogel-Fulcher suggesting the relaxor nature of the compound. The presence of polar nanoregions was confirmed by the presence of superlattice reflections in electron diffraction patterns.

The doping of tungsten into $\mathrm{SrBi}_{2} \mathrm{Ta}_{2} \mathrm{O}_{9}$ was found to provide an increase in the electrical resistivity as much as two to three orders of magnitude, which was attributed to the suppression of oxygen vacancies. The Curie temperature also increased. $^{26}$

The frequency and temperature dependence dielectric characterization in $\mathrm{Bi}_{4} \mathrm{Ti}_{2} \mathrm{Nb}_{0.5} \mathrm{Fe}_{0.5} \mathrm{O}_{12}$ ceramics has suggested a normal and displacive-type ferroelectric with a transition temperature of $903 \mathrm{~K}$. The ac conductivity was analyzed considering the Universal power law of Jonscher. ${ }^{27}$

A sharp ferroelectric-paraelectric phase transition has been reported for small concentration of neodymium in $\mathrm{Bi}_{3-x}$ $\mathrm{Nd}_{x} \mathrm{NbTiO}_{9}$ ceramics, whereas a diffuse phase transition was observed at higher neodymium content. ${ }^{28}$ The results have suggested that $\mathrm{Nd}^{3+}$ doping can inhibit the generation of oxygen vacancies. The dc conduction at low $\mathrm{Nd}^{3+}$ doping at high temperature has been attributed to an extrinsic p-type mechanism, which changes to an intrinsic mechanism at higher neodymium concentrations.

In the case of intergrowth $\mathrm{BaBi}_{2} \mathrm{Nb}_{2} \mathrm{O}_{9}-\mathrm{Bi}_{4} \mathrm{Ti}_{3} \mathrm{O}_{12}$ $\left(\mathrm{BaBi}_{6} \mathrm{Ti}_{3} \mathrm{Nb}_{2} \mathrm{O}_{21}\right)$ ceramic, a relaxor ferroelectric behavior has been reported with the highest transition temperature value of $909 \mathrm{~K}$ at $100 \mathrm{kHz}$ than those all of the known relaxor ferroelectric materials. ${ }^{16}$ The electrical analysis of the studied system has shown quite different properties concerning the two constituent oxides. Two anomalies were observed in the dielectric spectrum; one of them associated to the relaxor behavior.

Dielectric studies on lanthanum-modified $\mathrm{SrBi}_{2} \mathrm{Nb}_{2} \mathrm{O}_{9}$ ceramics have showed that the substitution of $\mathrm{Bi}_{2+}$ for $\mathrm{La}_{3+}$ provides a shift in the Curie point to lower temperature and a relaxor-like ferroelectric behavior. The results are associated to the cationic disordering at nanoscale on the A site of the perovskite blocks. $^{29}$

$\mathrm{BaBi}_{4} \mathrm{Ti}_{4} \mathrm{O}_{15}$ ceramics have been studied concerning the substitution of $\mathrm{Bi}^{2+}$ for $\mathrm{La}^{3+}$ showing that the diffuseness and relaxor behavior increase with increasing lanthanum concentration. ${ }^{30}$ It has been attributed to the compositional fluctuation induced by $\mathrm{La}^{3+}$, partly in perovskite and partly 
in $\left(\mathrm{Bi}_{2} \mathrm{O}_{2}\right)^{2+}$ layers. The freezing temperature and the dcconductivity also decreased with the lanthanum content. The last result has confirmed the decrease in the oxygen vacancy concentration with $\mathrm{La}^{3+}$ substitution.

The dielectric spectra of $\mathrm{Bi}_{2.5} \mathrm{Gd}_{1.5} \mathrm{Ti}_{3} \mathrm{O}_{12}$ ceramics showed a complex dielectric behavior with a transition temperature around $468 \mathrm{~K}$. The material exhibited a high ionic conductivity above that temperature and the activation energies for the presumably oxygen vacancies migration-related conductivity were found to be $E_{A}=0.98 \mathrm{eV}^{31}$

Solid solutions of gallium and indium doped $\mathrm{Bi}_{10} \mathrm{Ti}_{3} \mathrm{~W}_{3} \mathrm{O}_{30}$ were studied considering the dielectric behavior and differential scanning calorimetry data showing that both elements reduce the ferroelectric transition temperature. ${ }^{32}$ Three relaxation processes were evaluated from the $\mathrm{Ga}^{3+}$ and $\mathrm{In}^{3+}$ incorporation into the structure, which increased the oxygen vacancy concentration and then provided an increase in the electrical conductivity in the studied temperature range.

To complete this section, we are going to discuss some results concerning the dielectric and electric behavior on $\mathrm{Sr}_{0.5} \mathrm{Ba}_{0.5} \mathrm{Bi}_{2} \mathrm{Nb}_{2} \mathrm{O}_{9}$ ferroelectric ceramic system. A previous report showed two dielectric relaxation processes in a wide temperature range, i.e. below and above the relaxor peak region. ${ }^{33}$ The first relaxation process (around the relaxor peak) was associated to the relaxor-like ferroelectric behavior as the main cause; the second one (above the relaxor peak) was associated to the interaction between the dipoles, which form the microdomains that exist above the relaxor ferroelectric peak, and the electrons, which are due to the ionization of the oxygen vacancies. These results have suggested an important contribution of the electrical conductivity

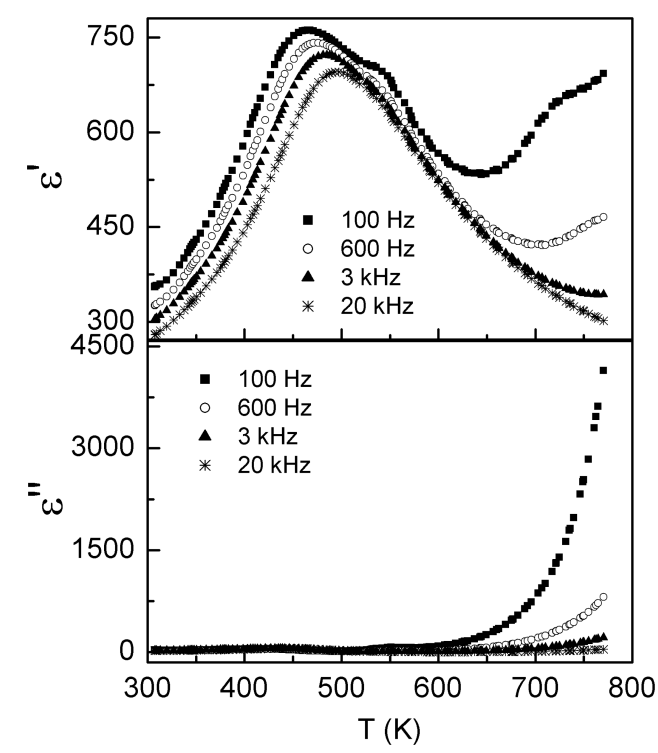

Fig. 3. Temperature dependence of the real $\left(\varepsilon^{\prime}\right)$ and imaginary $\left(\varepsilon^{\prime \prime}\right)$ parts of the dielectric permittivity, at various frequencies, for the $\mathrm{Sr}_{0.5} \mathrm{Ba}_{0.5} \mathrm{Bi}_{2} \mathrm{Nb}_{2} \mathrm{O}_{9}$ ferroelectric ceramic. mechanisms to the relaxation processes above the relaxor peak region, which has been the objective of new researches.

Figure 3 shows the temperature dependence of the real $\left(\varepsilon^{\prime}\right)$ and imaginary $\left(\varepsilon^{\prime \prime}\right)$ parts of the dielectric permittivity for several low and medium frequencies. It can be observed that the maximum value of $\varepsilon^{\prime}$ decreases with the increase of the frequency and the corresponding temperature $\left(T_{m}\right)$ shift up to higher temperatures. There is a little peak around $550 \mathrm{~K}$, which is observed in both dielectric parameters for the lower frequencies. This anomalous behavior disappears when the frequency increases, being associated to conductivity losses. For the higher temperatures zone (above $670 \mathrm{~K}$ approximately) an increases of $\varepsilon^{\prime}$ is observed, especially for the lower frequencies. The imaginary part of the dielectric permittivity $\left(\varepsilon^{\prime \prime}\right)$ also shows an abrupt increase for the same temperature range, showing that the anomalous behavior in $\varepsilon^{\prime}(T)$ and the high values of $\varepsilon^{\prime \prime}$ are attributed to the same mechanism, the conductivity losses. The typical maximum value in $\varepsilon^{\prime \prime}$, which should be observed around the ferroelectric-paraelectric phase transition temperature, can be only observed for higher frequencies. ${ }^{33}$ This result can be related to the rapid increase in the imaginary part of the dielectric permittivity. The maximum values were observed at lower temperatures than that of $T_{m}$, showing a significant dispersion with the frequency. ${ }^{33}$ The dispersion observed for the real and imaginary parts of the dielectric permittivity are typical of materials showing a relaxor behavior of the ferroelectricparaelectric transition.

The relaxor behavior observed for this ceramic material has been analyzed considering the incorporation of barium to the structure into the A site of the perovskite block and/or the incorporation to the bismuth site into the $\left(\mathrm{Bi}_{2} \mathrm{O}_{2}\right)^{2+}$ layers. ${ }^{2,6}$ The $\left(\mathrm{Bi}_{2} \mathrm{O}_{2}\right)^{2+}$ layer constrains the size of the perovskite block. ${ }^{18}$ The incorporation of the $\mathrm{Ba}^{2+}$ in both sites, therefore, occurs to equilibrate the lattice dimensions between the $\left(\mathrm{Bi}_{2} \mathrm{O}_{2}\right)^{2+}$ layers and the perovskite block. ${ }^{6,11}$ The ionic radius of $\mathrm{Ba}^{2+}(1.61 \AA)$ in 12th coordination (A-site) is higher than that of $\mathrm{Sr}^{2+}(1.44 \AA)$, which should provide an increase of the lattice parameters. Its ionic radius in 8th coordination (bismuth site) is higher (1.42 $\AA$ ) than that of $\mathrm{Bi}^{3+}$ $(1.17 \AA)$, but is smaller than that of its radius for the A-site. Substitution of $\mathrm{Ba}^{2+}$ on the $\mathrm{Bi}^{3+}$ site will reduce, therefore, the interlayer strain. Thus, the incorporation of the $\mathrm{Ba}^{2+}$ in bismuth and A-site provides the equilibrium of the lattice dimensions between the $\left(\mathrm{Bi}_{2} \mathrm{O}_{2}\right)^{2+}$ layers and the perovskite blocks. ${ }^{6}$ The incorporation of barium to the bismuth site can lead to an inhomogeneous distribution of barium and local charge imbalance in the layered structure ${ }^{2}$; the charge balance requires that the local negative charge resulting from the substitution be compensated by the formation of oxygen vacancies. These oxygen vacancies could influence in the dielectric response of the material.

The dielectric relaxation processes were analyzed from these results in a previous paper, for temperatures below and above the relaxor peak region, considering the relaxor 
behavior and the possible contribution of the electrical conductivity mechanisms. ${ }^{33}$ For temperatures above the relaxor peak region an important contribution of the electrical conductivity mechanisms to the relaxation processes was suggested. Therefore, we are going to focus our analysis for temperatures higher than $650 \mathrm{~K}$.

The anomaly behavior at the higher temperature region (above $670 \mathrm{~K}$ approximately) for the real part of the dielectric permittivity disappears when the frequency increases, showing that it could be related to a low-frequency relaxation process. ${ }^{33}$ Considering the oxygen vacancies, which could be generated due to the $\mathrm{Ba}^{2+}$ ions incorporation to the $\mathrm{Bi}^{3+}$ sites, the anomaly could be correlated with a low-frequency relaxation process due to oxygen vacancies. Conduction electrons could be created by the ionization of oxygen according to:

$$
\begin{aligned}
& V_{\mathrm{o}} \leftrightarrow V_{\mathrm{o}}^{\prime}+e^{\prime}, \\
& V_{\mathrm{o}} \leftrightarrow V_{\mathrm{o}}^{\prime \prime}+e^{\prime},
\end{aligned}
$$

where $V_{\mathrm{o}}, V_{\mathrm{o}}^{\prime}$ and $V_{\mathrm{o}}^{\prime \prime}$ represent, respectively the neutral, single- and doubly-ionized oxygen vacancies.

Figure 4 shows the frequency dependence of $\varepsilon^{\prime}$ and $\varepsilon^{\prime \prime}$, at several temperatures for the higher temperature zone. Two characteristic regions are observed suggesting two different relaxation processes. The first one is observed at the lower frequency range (until $2 \mathrm{kHz}$ approximately) showing a strong dispersive region where both the real and the imaginary parts of the dielectric permittivity can be described by a fractional power relation with the frequency $\left[\varepsilon^{\prime}(\omega), \varepsilon^{\prime \prime}(\omega) \propto \omega^{n-1}\right]$. The potential law behavior suggests that the so-called universal relaxation law holds for the ceramic system. ${ }^{34,35}$ The strong

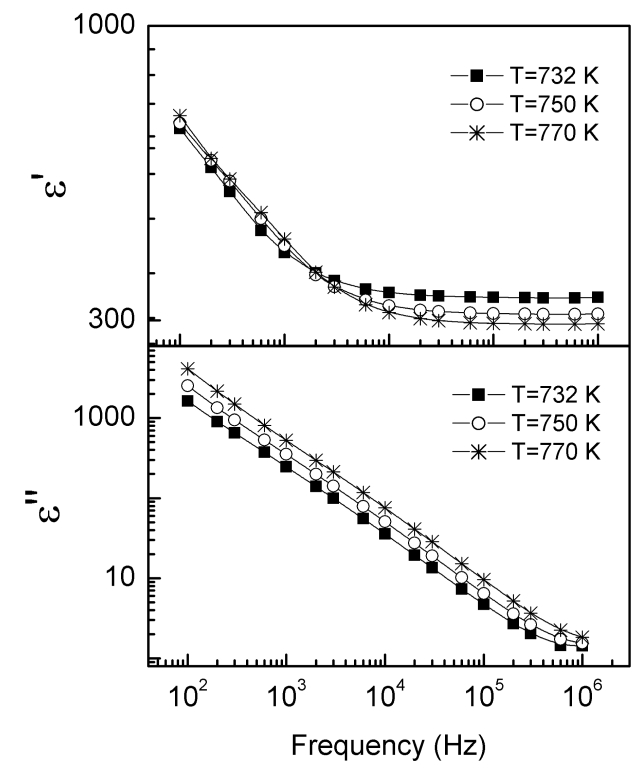

Fig. 4. Frequency dependence of the real $\left(\varepsilon^{\prime}\right)$ and imaginary $\left(\varepsilon^{\prime \prime}\right)$ parts of the dielectric permittivity, at several temperatures for the higher temperature zone, for the $\mathrm{Sr}_{0.5} \mathrm{Ba}_{0.5} \mathrm{Bi}_{2} \mathrm{Nb}_{2} \mathrm{O}_{9}$ ferroelectric ceramic. low-frequency dispersion may arise from the same type of mechanism as that is responsible for the usual universal response. Jonscher has suggested that the dispersion may be caused by the presence of impurities and the crystalline imperfections that affect the progress of charge carriers through a lattice. ${ }^{36}$ The conducting species moving by discontinuous jumps interact with another in a manner demanded by the screened hopping mechanism of the non-Debye analysis (a cooperative hopping). The dispersion at low frequencies depends upon transport of charges in the system and on the presence of blocking or nonblocking electrodes. The natural limit of this process is the formation of a fully developed space charge barrier of the Schottky type. It is not to be confused with the familiar polarization effects found at low frequencies, caused by the use of blocking electrodes; at low frequencies the charge carriers respond by moving bodily, by a sequence of activated hops, towards the appropriate electrode. This transition of charge within the bulk therefore produces an increase in the dielectric permittivity.

The second relaxation process is observed at the higher frequencies zone (above $2 \mathrm{kHz}$ ), where $\varepsilon^{\prime}$ is almost constant and $\varepsilon^{\prime \prime}$ again follows a power law $\varepsilon^{\prime \prime}(\omega) \propto \omega^{n-1}$. This behavior is associated to conductivity processes and it is known for many materials to be usually associated with the polarization of slowly mobile charges. ${ }^{34,35}$ The observed behavior could be described by the inter-cluster exchange mechanism, which has been proposed by the Dissado and Hill theory. ${ }^{37,38}$

The theory considers condensed matter as being composed of clusters, with each cluster is a spatially limited region with a partially regular structural order of individual units. Two kinds of interactions are considered; intra-cluster motions and intercluster exchanges, and each of these processes will give their own characteristic contribution to the dielectric permittivity function. The intra-cluster motion, which is regarded as analogous to the flipping of dipoles for the dipoles case, is now due to charge hopping between sites within the cluster reducing the overall cluster polarization. The inter-cluster exchange is quite dissimilar to that in the dipolar model, in the sense that the charges are exchanged between clusters.

In the inter-cluster exchange mechanism, when an ion hops to an available site over a range larger than the cluster size, its motion are no longer correlated with those of the donor cluster but rather with those of the acceptor cluster. Hence, charge transport over limited distances within the system is regarded as an effective charge displacement from a donor cluster, which becomes ionized, to an acceptor cluster, which becomes charged. As a consequence, an array of clusters exhibiting a distribution of occupying sites will be formed.

For a better understanding of the electrical conductivity influence in the material response, the complex modulus formalism can be used. ${ }^{39}$ Figure 5 shows the frequency dependence of the real $\left(M^{\prime}\right)$ and imaginary $\left(M^{\prime \prime}\right)$ parts of the complex modulus at various temperatures, as example of the behavior observed in the analyzed temperature region. It can 


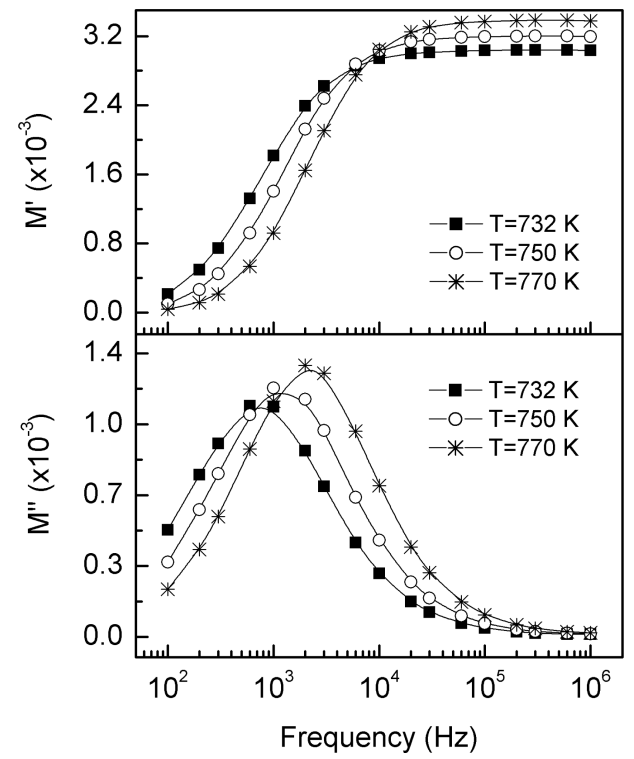

Fig. 5. Frequency dependence of the real $\left(M^{\prime}\right)$ and imaginary $\left(M^{\prime \prime}\right)$ parts of the complex modulus, at various temperatures, for the $\mathrm{Sr}_{0.5} \mathrm{Ba}_{0.5} \mathrm{Bi}_{2} \mathrm{Nb}_{2} \mathrm{O}_{9}$ ferroelectric ceramic.

be observed that $M^{\prime}$ increases with the frequency until a maximum value where it is nearly independent of the frequency. On the other hand, $M^{\prime \prime}$ shows a maximum value at a characteristic frequency named $\omega_{H}$, which increases with the temperature. Both $M^{\prime}$ and $M^{\prime \prime}$ show a strong temperature dependence suggesting a temperature dependence relaxation processes.

The temperature dependence of $\omega_{H}$ can be described by an Arrhenius relation in Eq. (1), were $\omega_{0}$ is the pre-exponential factor, $U_{H}$ is the activation energy associated with the relaxation process, $k_{B}$ is the Boltzmann constant and $T$ is the temperature.

$$
\omega_{H}=\omega_{o} \exp \left(\frac{-U_{H}}{k_{B} T}\right) .
$$

Figure 6 shows the Arrhenius dependence for $\omega_{H}$, whose values were obtained from the frequency dependence of $M^{\prime \prime}$ in the studied temperature range (Fig. 5). The solid line represents the fitting by using Eq. (1). It is also shown in Fig. 6 the activation energy value. The value of the pre-exponential factor is $2.6 \times 10^{12} \mathrm{~Hz}$, which is related to the ion hopping attempt frequency. ${ }^{40}$ The activation energy value is $1.27 \mathrm{eV}$, which is in the same order than in previous reports, which has been associated to doubly ionized oxygen vacancies. ${ }^{41,42}$ It could suggest that the relaxation process is associated to the oxygen vacancies. The creation of oxygen vacancies can be considered since the incorporation of barium to the bismuth site into the layer structure.

Figure 7 shows the frequency dependence of the electric conductivity for some temperatures, as example of the behavior observed in the studied temperature zone. From the electrical conductivity behavior, two relaxations processes can be considered as it has been previously discussed. The

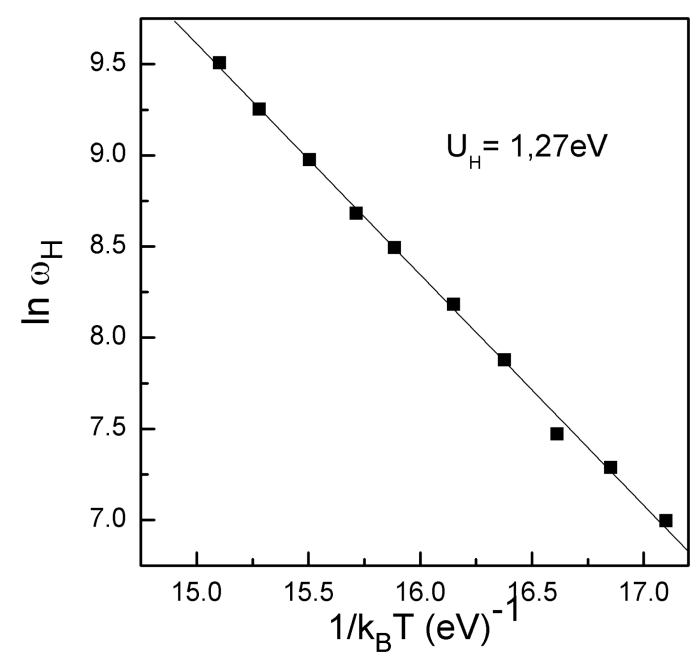

Fig. 6. Arrhenius dependence for $\omega_{H}$, whose values were obtained from the frequency dependence of $M^{\prime \prime}$ in the studied temperature range, for the $\mathrm{Sr}_{0.5} \mathrm{Ba}_{0.5} \mathrm{Bi}_{2} \mathrm{Nb}_{2} \mathrm{O}_{9}$ ferroelectric ceramic. The solid line represents the fitting by using Eq. (1).

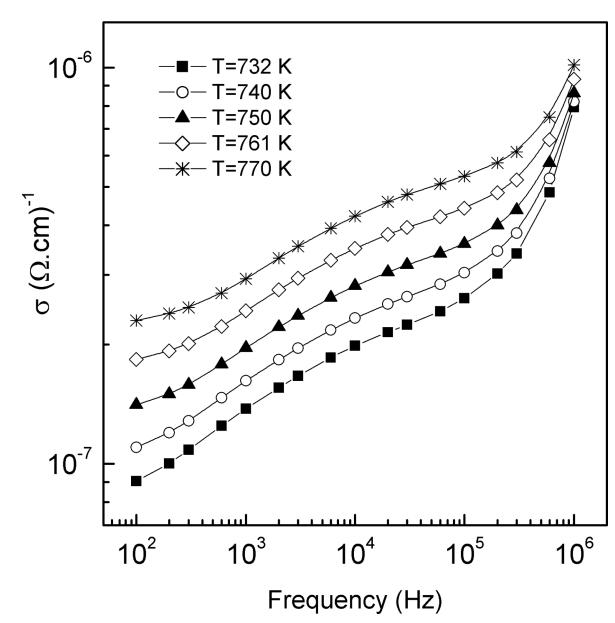

Fig. 7. Frequency dependence of the electric conductivity, at several temperatures, for the $\mathrm{Sr}_{0.5} \mathrm{Ba}_{0.5} \mathrm{Bi}_{2} \mathrm{Nb}_{2} \mathrm{O}_{9}$ ferroelectric ceramic.

first one can be observed in the same frequency range where a peak for $M^{\prime \prime}$ was observed; the second one appears for the higher frequencies.

Unfortunately, from this dependence it is quite difficult to determinate the dc component of the electrical conductivity $\left(\sigma_{d c}\right)$. The ac conductivity $(\sigma)$ can be defined by using Eq. (2) in terms of the real $\left(M^{\prime}\right)$ and imaginary $\left(M^{\prime \prime}\right)$ part of the complex modulus, were $\omega$ is dc frequency and $\varepsilon_{o}$ is the vacuum dielectric permittivity.

Considering the lower frequencies range, the dc conductivity could be estimated by using Eq. (3), where $M_{\infty}=$ $1 / \varepsilon_{\infty}\left(\varepsilon_{\infty}\right.$, high frequency dielectric permittivity), $\tau$ is the relaxation time $\left(\tau=1 / \omega_{H}\right), \beta$ reflects the deviation from dc Debye-type relaxation $(0<\beta<1)$ and $\Gamma(1 / \beta)$ is the Gamma function evaluated in $1 / \beta \cdot{ }^{43,44} \beta$ can be defined as 


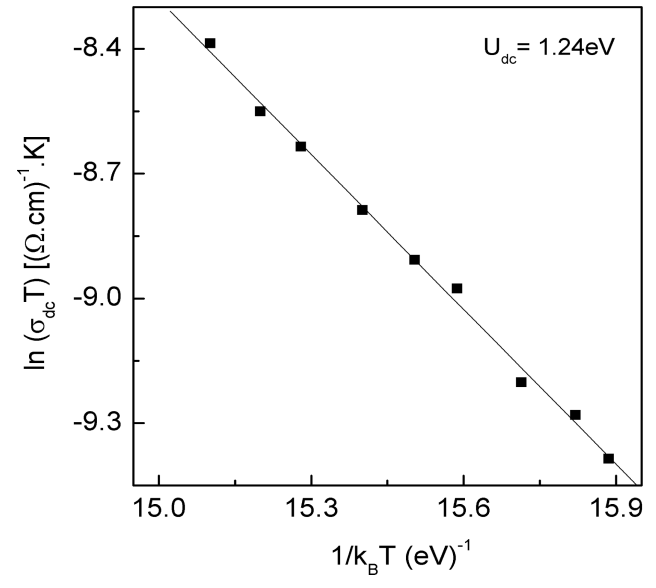

Fig. 8. Arrhenius dependence for the dc component of the electrical conductivity $\left(\sigma_{\mathrm{dc}}\right)$, whose values were obtained by using Eq. (3), for the $\mathrm{Sr}_{0.5} \mathrm{Ba}_{0.5} \mathrm{Bi}_{2} \mathrm{Nb}_{2} \mathrm{O}_{9}$ ferroelectric ceramic. The solid line represents the fitting by using Eq. (4).

1.14/FWHM, where FWHM is the full-width half-maximum of the imaginary part of the electric modulus $\left(M^{\prime \prime}\right) .{ }^{43}$

$$
\begin{aligned}
\sigma(\omega) & =\omega \varepsilon_{o}\left(\frac{M^{\prime \prime}}{M^{\prime 2}+M^{\prime \prime 2}}\right), \\
\sigma_{\mathrm{dc}} & =\frac{\varepsilon_{o}}{M_{\infty} \tau}\left(\frac{\beta}{\Gamma(1 / \beta)}\right) .
\end{aligned}
$$

Figure 8 shows the Arrhenius dependence for the $\sigma_{\mathrm{dc}}$ values, which were obtained by using Eq. (3). Note that a reduced temperature region was observed concerning the studied temperature range; for the lower temperatures it was not a clear peak for $M^{\prime \prime}$. The solid line represents the fitting by using Eq. (4), where $\sigma_{o}$ is a pre-exponential factor and $U_{\mathrm{dc}}$ is the activation energy of the process. It is also shown in Fig. 6 the corresponding activation energy value.

$$
\sigma_{\mathrm{dc}} T=\sigma_{o} \exp \left(\frac{-U_{\mathrm{dc}}}{k_{B} T}\right) .
$$

The $U_{\mathrm{dc}}$ value of the activation energy is near to the value of activation energy for the relaxation process, which suggests a strong influence of the electrical conductivity processes in the relaxation process. The results show that the electrical conduction is governed by the thermally excitation of carries from the oxygen vacancies. ${ }^{45}$ The hopping of the electrons, which appears due to the double ionization of the oxygen vacancies, could contribute to the dielectric relaxation process and its long-distance movement to the electrical conduction.

\section{Piezoelectricity}

An important number of works could be cited concerning the piezoelectric studies on the Aurivillius family of ferroelectric materials. In the present section, the most important results from the last 10 years will be presented.
Researches concerning Aurivillius-type materials for high temperature piezoelectrics have been reported by Pardo et al. considering $\left(\mathrm{Bi}_{3} \mathrm{TiNbO}_{9}\right)_{x}\left(\mathrm{SrBi}_{2} \mathrm{Nb}_{2} \mathrm{O}_{9}\right)_{1-x}$ ceramics. ${ }^{46} \mathrm{Cer}-$ amics with high transition temperatures, $d_{33}$ values of $11 \mathrm{pC} /$ $\mathrm{N}$ and $k_{t}$ values of $9 \%$ have been reported, which are good results for piezoelectric applications at high temperatures. Similar studies have been reported for bismuth-layer $\mathrm{Ca}_{x} \mathrm{Bi}_{4} \mathrm{Ti}_{3+x} \mathrm{O}_{12+3 x}$ ceramics showing that the electrical conductivity values are lower than those measured on other compounds of the Aurivillius ferroelectric family. The high electrical resistivity values have provided a better poling process of the ceramic samples. The results have suggested that these materials could be used for high-temperature piezoelectric applications. ${ }^{47}$

The effect of lithium, cerium and potassium-doped $\mathrm{CaBi}_{4} \mathrm{Ti}_{4} \mathrm{O}_{15}$ layered-structured ceramics has been studied by Yan et al., which has shown that simultaneous substitution by using lithium-cerium or potassium-cerium can improve the electrical resistivity at high temperatures and also the $d_{33}$ piezoelectric coefficient of the modified ceramics. ${ }^{48}$

Yan et al. has reported the study concerning the thermal depoling behavior in several Aurivillius ferroelectric ceramics with two-, three- and four-layers. ${ }^{49}$ They have shown that the orthorhombic structured materials have better resistance to thermal depoling up to temperatures close to their Curie temperature than that of the monoclinic structure. There is an important reduction in $d_{33}$ for the monoclinic structure well before its corresponding transition temperature. The monoclinic structure generates more non- $180^{\circ}$ ferroelectric domain structures than those of the orthorhombic phase, whose thermal instability has a significant contribution to the thermal depoling behavior of the material.

The electrical properties of the $\mathrm{Bi}_{3} \mathrm{NbTiO}_{9}$-based ceramics considering acceptor doped have been also investigated by Yan et al. ${ }^{24}$ It has been reported that bandgap of the pure material and its Curie temperature are around $3.4 \mathrm{eV}$ and $1173 \mathrm{~K}$, respectively. For acceptor doped there is a lower temperature for the peak corresponding to the temperature dependence of the dielectric losses, which is explained considering an oxygen ion-jump mechanism. On the other hand, it has been discussed how the switching of thermally unstable non- $180^{\circ}$ domain walls provides an important depolarization below $773 \mathrm{~K}$ with the corresponding reduction in the piezoelectric parameter.

Aurivillius phase ceramics based on $\mathrm{Bi}_{4} \mathrm{Sr}_{n-3} \mathrm{Ti}_{n} \mathrm{O}_{3 n+3}$ with $n=3,4$ and 5 have been studied for piezoelectric applications. ${ }^{50}$ It has been shown that the electrical conductivity can be reduced for $n=4$ and 5, providing easier poling process. A piezoelectric coefficient $d_{33}$ around $25 \mathrm{pC} / \mathrm{N}$ was reported.

A four-layer Aurivillius type structure has been reported for cesiumdoped $\mathrm{K}_{0.5} \mathrm{La}_{0.5} \mathrm{Bi}_{4} \mathrm{Ti}_{4} \mathrm{O}_{15}$ ceramics showing the higher value of $d_{33}$ piezoelectric coefficient than those of other modified potassium lanthanum bismuth titanate ceramics. ${ }^{51}$ The composition with the higher $d_{33}$ value shows the higher 
electromechanical coupling and the lower dielectric losses. The results have been explained considering that the incorporation of the cesium increases the resistivity, making the poling easier, and then provides better piezoelectric properties. Similar results have been found in lithium-cerium doping in Aurivillius phase material $\mathrm{Na}_{0.25} \mathrm{~K}_{0.25} \mathrm{Bi}_{4.5} \mathrm{Ti}_{4} \mathrm{O}_{15}{ }^{52}$ and cerium modified $\mathrm{Na}_{0.5} \mathrm{La}_{0.5} \mathrm{Bi}_{4} \mathrm{Ti}_{4} \mathrm{O}_{15}$ ceramics. ${ }^{53}$

Other studies on Aurivillius-type materials have shown good properties for piezoelectric applications at high temperatures. ${ }^{54}$ The analysis carried out on $\left(\mathrm{Sr}_{1-x} \mathrm{Ca}_{x}\right)_{2} \mathrm{Bi}_{4} \mathrm{Ti}_{5} \mathrm{O}_{18}$ ceramics have shown high Curie transition temperature, large piezoelectric coefficient $d_{33}$ and very good temperature stability.

Intergrowth $\mathrm{BaBi}_{2} \mathrm{Nb}_{2} \mathrm{O}_{9}-\mathrm{Bi}_{4} \mathrm{Ti}_{3} \mathrm{O}_{12} \quad\left(\mathrm{BaBi}_{6} \mathrm{Ti}_{3} \mathrm{Nb}_{2} \mathrm{O}_{21}\right)$ Aurivillius ferroelectric ceramic has been studied concerning the $d_{33}$ piezoelectric coefficient behavior. A piezoelectric signal was observed even in the paraelectric phase. ${ }^{16}$ The results have indicated that there is spontaneous polarization above the transition temperature, which is typical for relaxor ferroelectric behavior.

The influence of dopants such as magnesium, strontium calcium and barium on the properties of $\mathrm{BaBi}_{3.8} \mathrm{M}_{0.2}\left(\mathrm{Ti}_{3.8}-\right.$ $\left.\mathrm{Nb}_{0.2}\right) \mathrm{O}_{15}$, where $\mathrm{M}$ represents the dopant element, has been studied by Chakrabarti and Bera. ${ }^{55}$ Better results for the dielectric permittivity and the $d_{33}$ piezoelectric coefficient were reported for $\mathrm{Mg}$-based compound.

On the other hand, solid solutions of the Aurivillius type $\mathrm{Ba}_{x}\left(\mathrm{Na}_{0.5} \mathrm{Bi}_{0.5}\right)_{1-x} \mathrm{Bi}_{4} \mathrm{Ti}_{4} \mathrm{O}_{15}$ have been studied considering the barium doping and its effect on the dielectric and piezoelectric properties. The results showed that the barium incorporation leads to a decrease in the Curie temperature, enhancing the permittivity peak and raising the piezoelectric constant. $^{56}$

Yi et al. have recently reported the studies carried out on $\mathrm{Bi}_{5-x} \mathrm{La}_{x} \mathrm{TiNbWO}_{15}$ and $\mathrm{Bi}_{7-x} \mathrm{La}_{x} \mathrm{Ti}_{4} \mathrm{NbO}_{21}$ ceramics concerning ferro- and piezoelectric properties. ${ }^{57}$ They showed a semiconducting behavior and low piezoelectric coefficients for the first compound. For the second ceramic composition a promising material for piezoelectric applications has been reported.

It is known that the piezoelectric activity of the bismuth layered-structured ferroelectric ceramics is limited due to the two-dimensional orientation restriction of the spontaneous polarization rotation and the coercive electric field values. ${ }^{58,59}$ The textured processing has been reported as an efficient way to increase the piezoelectric properties of these materials. The $d_{33}$ and $k_{t}$ parameters have been improved two or three times than those of conventionally sintered ceramics, showing promising materials for piezoelectric applications. ${ }^{58,59}$

Finally, Fig. 9 shows an example of a piezoelectric response for $\mathrm{Sr}_{0.7} \mathrm{Ba}_{0.3} \mathrm{Bi}_{2} \mathrm{Nb}_{2} \mathrm{O}_{9}$ composition at room temperature. A large electromechanical anisotropy is observed between the thickness and the planar modes. There is not resonance signal for the planar mode; the corresponding coupling factor is $k_{p} \cong 0$. There is a very $\operatorname{good}$ resonance

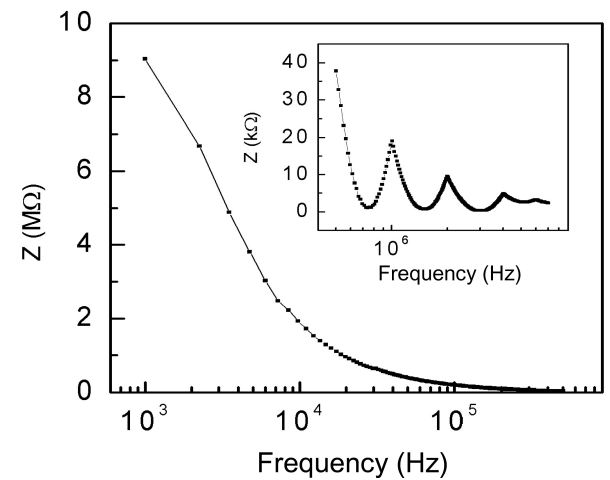

Fig. 9. Piezoelectric response for $\mathrm{Sr}_{0.7} \mathrm{Ba}_{0.3} \mathrm{Bi}_{2} \mathrm{Nb}_{2} \mathrm{O}_{9}$ composition at room temperature.

signal for the thickness mode. Piezoelectric coefficients $d_{33}$ and $g_{33}$ around $32 \mathrm{pC} / \mathrm{N}$ and $18 \times 10^{-3} \mathrm{Vm} / \mathrm{N}$ were obtained.

It is known that the spontaneous polarization of ferroelectric ceramics originates from the alignment of ferroelectric domains parallel to the poling field, while the piezoelectric properties are dominated by intrinsic lattice contributions and extrinsic contributions from movements of non- $180^{\circ}$ domain walls. So, the replacement of $\mathrm{Sr}^{2+}$ by $\mathrm{Ba}^{2+}$, in the A-site, may induce the rotation and tilting of the octahedral because of the different ionic radii. It can be beneficial to the movements of non- $180^{\circ}$ domain walls, resulting in the enhancement of piezoelectric properties.

\section{Pyroelectricity}

The bismuth titanate $\left(\mathrm{Bi}_{4} \mathrm{Ti}_{3} \mathrm{O}_{12}\right)$ is one of the most famous ferroelectric material of Aurivillius family. ${ }^{60}$ Several studies showed that it has good properties for piezoelectric applications at high temperatures; its ferroelectric-paraelectric phase transition temperature is very high $(948 \mathrm{~K})$. Also, this material showed an electro-optical switching behavior, which has suggested a promising material for optical applications too. ${ }^{61-64}$

On the other hand, several works have shown the researches carried out concerning the nanosized powders preparation of bismuth titanate, which has allowed obtaining ceramics with excellent pyroelectric properties for applications as detectors. ${ }^{65-69}$

Hou and colleagues have also studied the temperature dependence of the pyroelectric coefficient on niobium and thallium modified bismuth titanate. ${ }^{40}$ They have reported a pyroelectric coefficient of $12 \mu \mathrm{C} / \mathrm{m}^{2} \mathrm{~K}$ at room temperature, which is better than that of pure bismuth titanate ceramics. ${ }^{65} \mathrm{It}$ also discussed that the behavior for the pyroelectric coefficient is in agreement with the temperature dependence of the dielectric permittivity and the piezoelectric coefficient $d_{33}{ }^{70}$

The present authors have developed some researches concerning the pyroelectric behavior for $\mathrm{Sr}_{x-1} \mathrm{Ba}_{x} \mathrm{Bi}_{2} \mathrm{Nb}_{2} \mathrm{O}_{9}$ ceramics, where we have not found previous reports. Figure 10 shows the temperature dependence of the electrical 


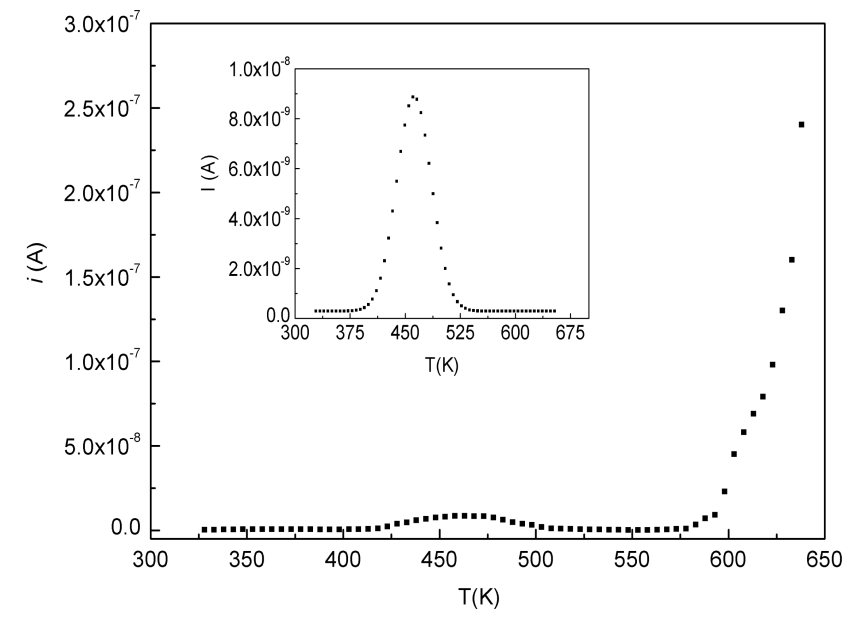

Fig. 10. Temperature dependence of the electrical current $(i)$ for $\mathrm{SrBi}_{2} \mathrm{Nb}_{2} \mathrm{O}_{9}$ in a wide temperature range. The pyroelectric current $(I)$ is shown in the inset of the figure.

current $(i)$ for $\mathrm{SrBi}_{2} \mathrm{Nb}_{2} \mathrm{O}_{9}$ in a wide temperature range. It can be observed an increase of $i$ with the temperature until a maximum value and then a decrease of its value; for temperatures higher than $573 \mathrm{~K}$ the values of $i$ rise with temperature. For the pyroelectric materials, the behavior of the electrical current usually shows an increase with temperature until a maximum value and then a decrease until the transition temperature $\left(T_{m}\right)$ where the current must be null. In many cases this behavior is not observed because the electrical current is not null at $T_{m}$, showing an important contribution of the electrical conductivity in the response of the material. For $\mathrm{SrBi}_{2} \mathrm{Nb}_{2} \mathrm{O}_{9}$ ceramic, $T_{m}$ is around $640 \mathrm{~K}$ suggesting that the increase of $i$ above $573 \mathrm{~K}$ should be associated to electrical conductivity. From the experimental data, the pyroelectric contribution $(I)$ wasseparated from the total response by using a numerical method. ${ }^{71}$ The temperature dependence of the pyroelectric current $(I)$ is shown in the inset of Fig. 10. A pyroelectric coefficient of $34 \mu \mathrm{C} / \mathrm{m}^{2} \mathrm{~K}$ was obtained around room temperature, which is a higher value than those of other reports for Aurivillius materials. ${ }^{40}$

\section{Summary}

Bismuth layer-structure ferroelectrics have attracted considerable interest because of their technological importance. Several works have been reported on the doping effect on the improvement of the properties of these ferroelectric materials. Most of them have been conducted to study the structural and dielectric properties; especially the nature of the relaxor behavior has received attention. Other researches have been carried out concerning piezoelectric and pyroelectric behavior of these materials. The present review has shown a general overview of the progress in the studies on the ferroelectric ceramics from the Aurivillius family.

\section{Acknowledgments}

The authors want to thank the ICTP for financial support of Latin-American Network of Ferroelectric Materials. Special thanks to Dr. E. B. Araújo (Universidade Estadual Paulista, Ilha Solteira, SP - Brazil) and Dr. A. Franco Júnior (Universidade Federal de Goiás, Goiânia, GO - Brazil).

\section{References}

${ }^{1}$ K. M. Rabe, Ch. H. Ahn and J.-M. Triscone (eds.), Physics of Ferroelectrics. A Modern Perspective (Springer-Verlag, Berlin Heidelberg, 2007).

${ }^{2}$ C. Miranda, M. E. V. Costa, M. Avdeev, A. L. Kholkin and J. L. Baptista, Relaxor properties of Ba-based layered perovskites, J. Eur. Ceram. Soc. 21, 1303 (2001).

${ }^{3}$ A. L. Kholkin, M. Avdeev, M. E. V. Costa, J. L. Baptista and S. N. Dorogotsev, Dielectric relaxation in Ba-based layered perovskites, Appl. Phys. Lett. 79, 662 (2001).

${ }^{4}$ H. N. Lee, D. Hesse, N. Zakharov and U. Gösele, Ferroelectric $\mathrm{Bi}_{3.25} \mathrm{La}_{0.75} \mathrm{Ti}_{3} \mathrm{O}_{12}$ films of uniform a-axis orientation on silicon substrates, Science 296, 2006 (2002).

${ }^{5}$ T. Watanabe and H. Fuankubo, Controlled crystal growth of layered-perovskite thin films as an approach to study their basic properties, J. Appl. Phys. 100, 051602 (2006).

${ }^{6}$ M. S. Haluska and S. T. Misture, Crystal structure refinements of the three-layer Aurivillius ceramics $\mathrm{Bi}_{2} \mathrm{Sr}_{2-x} \mathrm{~A}_{x} \mathrm{Nb}_{2} \mathrm{TiO}_{12}(\mathrm{~A}=\mathrm{Ca}$, $\mathrm{Ba} ; \mathrm{x}=0,0.5,1)$ using combined $\mathrm{x}$-ray and neutron powder diffraction, J. Solid State Chem. 177, 1965 (2004).

${ }^{7}$ S. M. Blake, M. J. Falconer, M. McCreedy and P. Lightfoot, Cation disorder in ferroelectric Aurivillius phases of the type $\mathrm{Bi}_{2} \mathrm{ANb}_{2} \mathrm{O}_{9}$ (A=Ba, Sr, Ca), J. Mater. Chem. 7, 1609 (1997).

${ }^{8} \mathrm{~S}$. Huang, Ch. Feng, L. Chen and Q. Wang, Relaxor behavior of $\mathrm{Sr}_{1-x} \mathrm{Ba}_{x} \mathrm{Bi}_{2} \mathrm{Nb}_{2} \mathrm{O}_{9}$ ceramics, J. Am. Ceram. Soc. 89, 328 (2006).

${ }^{9}$ B. Wachsmuth, E. Zschech, N. W. Thomas, S. G. Brodie, S. J. Gurman, S. Baker and S. C. Bayliss, Structure model of Aurivillius compounds, Phys. Status Solidi (a) 135, 59 (1993).

${ }^{10}$ D. Nelis, D. Mondelaers, G. Vanhoyland, A. Hardy, K. Van Werde, H. Van den Rul, M. K. Van Bael, J. Mullens, L. C. Van Poucke and J. D'Haen, Synthesis of strontium bismuth niobate $\left(\mathrm{SrBi}_{2} \mathrm{Nb}_{2} \mathrm{O}_{9}\right)$ using an aqueous acetate-citrate precursor gel: Thermal decomposition and phase formation, Thermochim. Acta 426, 39 (2005).

${ }^{11}$ Ismunandar and B. J. Kennedy, Effect of temperature on cation disorder in $\mathrm{ABi}_{2} \mathrm{Nb}_{2} \mathrm{O}_{9}(\mathrm{~A}=\mathrm{Sr}, \mathrm{Ba})$, J. Mater. Chem. 9, 541 (1999).

${ }^{12} \mathrm{M}$. Mahesh Kumar and Z.-G. Ye, Dielectric and electric properties of donor- and acceptor-doped ferroelectric $\mathrm{SrBi}_{2} \mathrm{Ta}_{2} \mathrm{O}_{9}, J$. Appl. Phys. 90, 934 (2001).

${ }^{13}$ Ismunandar and B. J. Kennedy, Structure of $\mathrm{ABi}_{2} \mathrm{Nb}_{2} \mathrm{O}_{9}(\mathrm{~A}=\mathrm{Sr}$, $\mathrm{Ba}$ ): Refinement of powder neutron diffraction data, J. Solid State Chem. 126, 136 (1996).

${ }^{14} \mathrm{~S}$. Borg, G. Svensson and J. Bovin, Structure study of $\mathrm{Bi}_{2.5} \mathrm{Na}_{0.5} \mathrm{Ta}_{2} \mathrm{O}_{9}$ and $\mathrm{Bi}_{2.5} \mathrm{Na}_{m-1.5} \mathrm{Nb}_{m} \mathrm{O}_{3 m+3}(\mathrm{~m}=2-4)$ by neutron powder diffraction and electron microscopy, J. Solid State Chem. 167, 86 (2002).

${ }^{15}$ C. A. Hervoches, A. Snedden, R. Riggs, S. H. Kilcoyne, P. Manuel and P. Lightfoot, Structural behavior of the four-layer Aurivillius-phase ferroelectrics $\mathrm{SrBi}_{4} \mathrm{Ti}_{4} \mathrm{O}_{15}$ and $\mathrm{Bi}_{5} \mathrm{Ti}_{3} \mathrm{FeO}_{15}$, J. Solid State Chem. 164, 280 (2002). 
${ }^{16}$ H. Zhang, H. Yan and M. J. Reece, High temperature lead-free relaxor ferroelectric: Intergrowth Aurivillius phase $\mathrm{BaBi}_{2} \mathrm{Nb}_{2} \mathrm{O}_{9}-$ $\mathrm{Bi}_{4} \mathrm{Ti}_{3} \mathrm{O}_{12}$ ceramic, J. Appl. Phys. 107, 104111 (2010).

${ }^{17}$ R. D. Shannon, Revised effective ion radii and systematic studies of interatomic distances in halides and chalcogenides, Acta Crystallogr. A 32, 751 (1976).

${ }^{18}$ R. A. Armstrong and R. E. Newnham, Bismuth titanate solid solutions, Mater. Res. Bull. 7, 1025 (1972).

${ }^{19}$ M. García-Guaderrama, M. E. Botello-Zubiate, A. MarquezLucero, J. A. Matutes-Aquino and L. E. Fuentes-Cobas, Síntesis por rutas químicas y estructura cristalina de la fase Aurivillius $\mathrm{Bi}_{4} \mathrm{Ti}_{3} \mathrm{O}_{12}$, Rev. Mex. Fís. 50, 42 (2004) (in Spanish).

${ }^{20}$ D. Nuzhnyy, S. Kamba, P. Kužel, S. Veljko, V. Bovtun, M. Savinov, J. Petzelt, H. Amorín, M. E. V. Costa, A. L. Kholkin, Ph. Boullay and M. Adamczyk, Dynamics of the phase transitions in Bi-layered ferroelectrics with Aurivillius structure: Dielectric response in the terahertz spectral range, Phys. Rev. B 74, 134105 (2006).

${ }^{21}$ H. Zhang, H. Yan, H. Ning, M. J. Reece, M. Eriksson, Z. Shen, Y. Kan and P. Wang, The grain size effect on the properties of Aurivillius phase $\mathrm{Bi}_{3.15} \mathrm{Nd}_{0.85} \mathrm{Ti}_{3} \mathrm{O}_{12}$ ferroelectric ceramics, Nanotechnology 20, 385708 (2009).

${ }^{22}$ Y. Wu, M. J. Forbess, S. Seraji, S. J. Limmer, T. P. Chou, C. Nguyen and G. Z. Cao, Doping effect in layer structured $\mathrm{SrBi}_{2} \mathrm{Nb}_{2} \mathrm{O}_{9}$ ferroelectrics, J. Appl. Phys. 90, 5296 (2001).

${ }^{23}$ D. Ben Jennet, P. Marchet, M. El Maaoui and J. P. Mercurio, From ferroelectric to relaxor behaviour in the Aurivillius-type $\mathrm{Bi}_{4-x} \mathrm{Ba}_{x} \mathrm{Ti}_{3-x} \mathrm{Nb}_{x} \mathrm{O}_{12}(0<x<1.4)$ solid solutions, Mater. Lett. 59, 376 (2005).

${ }^{24}$ H. Yan, H. Zhang, Z. Zhang, R. Ubic and M. J. Reece, B-site donor and acceptor doped Aurivillius phase $\mathrm{Bi}_{3} \mathrm{NbTiO}_{9}$ ceramics, J. Eur. Ceram. Soc. 26, 2785 (2006).

${ }^{25}$ C. Karthik, N. Ravishankar, M. Maglione, R. Vondermuhll, J. Etourneau and K. B. R. Varma, Relaxor behavior of $\mathrm{K}_{0.5} \mathrm{La}_{0.5}$ $\mathrm{Bi}_{2} \mathrm{Ta}_{2} \mathrm{O}_{9}$ ceramics, Solid State Commun. 139, 268 (2006).

${ }^{26}$ I. Coondoo, A. K. Jha and S. K. Agarwal, Enhancement of dielectric characteristics in donor doped Aurivillius $\mathrm{SrBi}_{2} \mathrm{Ta}_{2} \mathrm{O}_{9}$ ferroelectric ceramics, J. Eur. Ceram. Soc. 27, 253 (2007).

${ }^{27}$ S. Kumar and K. B. R. Varma, Structural and dielectric properties of $\mathrm{Bi}_{4} \mathrm{Ti}_{2} \mathrm{Nb}_{0.5} \mathrm{Fe}_{0.5} \mathrm{O}_{12}$ ceramics, Solid State Commun. 146, 137 (2008).

${ }^{28}$ H. Zhang, H. Yan and M. J. Reece, The effect of Nd substitution on the electrical properties of $\mathrm{Bi}_{3} \mathrm{NbTiO}_{9}$ Aurivillius phase ceramics, J. Appl. Phys. 106, 044106 (2009).

${ }^{29}$ P. Fang, H. Fan, J. Li and F. Liang, Lanthanum induced larger polarization and dielectric relaxation in Aurivillius phase $\mathrm{SrBi}_{2-x} \mathrm{La}_{x} \mathrm{Nb}_{2} \mathrm{O}_{9}$ ferroelectric ceramics, J. Appl. Phys. 107, 064104 (2010).

${ }^{30}$ A. Chakrabarti and J. Bera, Effect of La-substitution on the structure and dielectric properties of $\mathrm{BaBi}_{4} \mathrm{Ti}_{4} \mathrm{O}_{15}$ ceramics, $J$. Alloys Compd. 505, 668 (2010).

${ }^{31}$ E. Masiukaite, J. Banys, R. Sobiestianskas, T. Ramoska, V. A. Khomchenko and D. A. Kiselev, Conductivity investigations of Aurivillius-type $\mathrm{Bi}_{2.5} \mathrm{Gd}_{1.5} \mathrm{Ti}_{3} \mathrm{O}_{12}$ ceramics, Solid State Ionics 188, 50 (2011).

${ }^{32}$ E. P. Kharitonova, D. A. Belov, A. V. Mosunov and V. I. Voronkova, Phase transition and electrical properties of gallium and indium doped $\mathrm{Bi}_{10} \mathrm{Ti}_{3} \mathrm{~W}_{3} \mathrm{O}_{30}$, Inorg. Mater. 47, 513 (2011).

${ }^{33}$ Y. González-Abreu, A. Peláiz-Barranco, E. B. Araújo and A. Franco Jr, Dielectric relaxation and relaxor behavior in bi-layered perovskites, Appl. Phys. Lett. 94, 262903 (2009).
${ }^{34}$ A. K. Jonscher, Dielectric Relaxation in Solids (Chelsea Dielectric Press, London, 1983).

${ }^{35}$ A. K. Jonscher, Universal Relaxation Law (Chelsea Dielectrics Press, London, 1996).

${ }^{36} \mathrm{~A}$. K. Jonscher, Low frequency dispersion in carrier-dominated dielectrics, Phil. Mag. B 38, 587 (1978).

${ }^{37}$ L. A. Dissado and R. M. Hill, A cluster approaches to the structure of imperfect materials and their relaxation spectroscopy, Proc. $R$. Soc. Lond. 131 (1983).

${ }^{38}$ L. A. Dissado and R. M. Hill, Anomalous low-frequency dispersion, J. Chem. Soc. Faraday Trans. 2, 291 (1984).

${ }^{39}$ C. Elissalde and J. Ravez, Ferroelectric ceramics: Defects and dielectric relaxations, J. Mater. Chem. 11, 1957 (2001).

${ }^{40}$ J. Hou, R. Vaish, Y. Qu, D. Krsmanovic, K. B. R. Varma and R. V. Kumar, Dielectric, pyroelectric and ferroelectric properties of $\mathrm{Bi}_{4} \mathrm{Ti}_{2.98} \mathrm{Nb}_{0.01} \mathrm{Ta}_{0.01} \mathrm{O}_{12}$ ceramics, Mater. Chem. Phys. 121, 32 (2010).

${ }^{41}$ S. A. Long and R. N. Blumenthal, Ti-rich nonstoichiometric $\mathrm{BaTiO}_{3}$ : II, Analysis of the defect structure, J. Am. Ceram. Soc. 54, 577 (1971).

${ }^{42} \mathrm{R}$. Waser, Bulk conductivity and defect chemistry of acceptordoped strontium titanate in the quenched state, J. Am. Ceram. Soc. 74, 1934 (1991).

${ }^{43}$ K. L. Ngai, R. W. Rendell and H. Jain, Anomalous isotope-mass effect in lithium borate glasses: Comparison with an unified relaxation model, Phys. Rev. B 30, 2133 (1984).

${ }^{44}$ J. R. Macdonald (ed.), Impedance Spectroscopy (John \& Sons, 2005).

${ }^{45}$ N. Zhong, S. Okamura, K. Uchiyama and T. Shiosaki, Singleionized-oxygen-vacancy-related dielectric relaxation in $\mathrm{Bi}_{3.25}$ $\mathrm{La}_{0.75} \mathrm{Ti}_{3} \mathrm{O}_{12}$ ferroelectric, Appl. Phys. Lett. 87, 252901 (2005).

${ }^{46}$ L. Pardo, A. Castro, P. Millán, C. Alemany, R. Jimenez and B. Jimenez, $\left(\mathrm{Bi}_{3} \mathrm{TiNbO}_{9}\right)_{x}\left(\mathrm{SrBi}_{2} \mathrm{Nb}_{2} \mathrm{O}_{9}\right)_{1-x}$ Aurivillius type structure piezoelectric ceramics obtained from mechanochemically activated oxides, Acta Mater. 48, 2421 (2000).

${ }^{47}$ C. Moure, V. Gil, J. Tartaj and P. Durán, Crystalline structure, dielectric and piezoelectric properties of bismuth-layer $\mathrm{Ca}_{x} \mathrm{Bi}_{4}$ $\mathrm{Ti}_{3+x} \mathrm{O}_{12+3 x}(x=1,2)$ compounds, J. Eur. Ceram. Soc. 25, 2447 (2005).

${ }^{48}$ H. Yan, Z. Zhang, W. Zhu, L. He, Y. Yu, Ch. Li and J. Zhou, The effect of $(\mathrm{Li}, \mathrm{Ce})$ and $(\mathrm{K}, \mathrm{Ce})$ doping in Aurivillius phase material $\mathrm{CaBi}_{4} \mathrm{Ti}_{4} \mathrm{O}_{15}$, Mater. Res. Bull. 39, 1237 (2004).

${ }^{49}$ H. Yan, H. Zhang and Michael J. Reece, Thermal depoling of high Curie point Aurivillius phase ferroelectric ceramics, Appl. Phys. Lett. 87, 082911 (2005).

${ }^{50} \mathrm{P}$. Ferrer, M. Algueró, J. E. Iglesias and A. Castro, Processing and dielectric properties of $\mathrm{Bi}_{4} \mathrm{Sr}_{n-3} \mathrm{Ti}_{n} \mathrm{O}_{3 n+3}(n=3,4$ and 5) ceramics obtained from mechanochemically activated precursors, J. Eur. Ceram. Soc. 27, 3641 (2007).

${ }^{51}$ Ch.-M. Wang, L. Zhao, J.-F. Wang, M.-L. Zhao, Z.-G. Gai, W.-B. $\mathrm{Su}$, J. Du and L.-M. Zheng, Piezoelectric and dielectric properties of cerium-modified Aurivillius type $\mathrm{K}_{0.5} \mathrm{La}_{0.5} \mathrm{Bi}_{4} \mathrm{Ti}_{4} \mathrm{O}_{15}$ ceramics, Mater. Chem. Phys. 114, 1004 (2009).

${ }^{52}$ Z.-G. Gai, J.-F. Wang, M.-L. Zhao, W.-B. Sun, S.-Q. Sun, B.-Q. Ming, P. Qi, L.-M. Zheng, J. Du, Ch.-M. Wang, S. Zhang and T. R. Shrout, The effect of $(\mathrm{Li}, \mathrm{Ce})$ doping in aurivillius phase material $\mathrm{Na}_{0.25} \mathrm{~K}_{0.25} \mathrm{Bi}_{4.5} \mathrm{Ti}_{4} \mathrm{O}_{15}$, Scr. Mater. 59, 115 (2008).

${ }^{53}$ Ch.-M. Wang, L. Zhao, J.-F. Wang, L.-M. Zheng, J. Du, M.-L. Zhao and Ch.-L. Wang, Cerium-modified Aurivillius-type sodium lanthanum bismuth titanate with enhanced piezoactivities, Mater. Sci. Eng. B 163, 179 (2009). 
${ }^{54}$ Z. Xu, R. Chu, J. Hao, Y. Zhang, Q. Chen, L. Zhao, G. Li and Q. Yin, Study on high temperature performances for bismuth layer-structured $\left(\mathrm{Sr}_{1-x} \mathrm{Ca}_{x}\right)_{2} \mathrm{Bi}_{4} \mathrm{Ti}_{5} \mathrm{O}_{18} \quad(0 \leq x \leq 1)$ ceramics, J. Alloys Compd. 487, 585 (2009).

${ }^{55} \mathrm{~A}$. Chakrabarti and J. Bera, Structure and ferroelectric properties of $\mathrm{BaBi}_{3.8} \mathrm{M}_{0.2}\left(\mathrm{Ti}_{3.8} \mathrm{Nb}_{0.2}\right) \mathrm{O}_{15}(\mathrm{M}=\mathrm{Mg}, \mathrm{Ca}, \mathrm{Sr}$ and $\mathrm{Ba})$ ceramics, Physica B 406, 2891 (2011).

${ }^{56} \mathrm{H}$. Du and X. Shi, Dielectric and piezoelectric properties of barium-modified Aurivillius-type $\mathrm{Na}_{0.5} \mathrm{Bi}_{4.5} \mathrm{Ti}_{4} \mathrm{O}_{15}$, J. Phys. Chem. Solids 72, 1279 (2011).

${ }^{57}$ Z. G. Yi, Y. X. Li and Y. Liu, Ferroelectric and piezoelectric properties of Aurivillius phase intergrowth ferroelectrics and the underlying materials design, Phys. Status Solidi (a) 208, 1035 (2011).

${ }^{58}$ G. L. Messing, S. Troiler-McKinstry, E. M. Sabolsky, C. Duran, S. Kown, B. Brahmaroutu, P. Park, H. Yilmaz, P. W. Rehrig, K. B. Eitel and E. Suvaci, Templated grain growth of textured piezoelectric ceramics, Crit. Rev. Solid State Mater. Sci. 29, 45 (2004).

${ }^{59}$ H. Yan, H. Zhang, R. Ubic, M. J. Reece, J. Liu, Z. Shen and Z. Zhang, A lead-free high-Curie-point ferroelectric ceramic, $\mathrm{CaBi}_{2} \mathrm{Nb}_{2} \mathrm{O}_{9}$, Adv. Mater. 17, 1261 (2005).

${ }^{60}$ J. F. Dorrian, R. E. Newnham and K. K. Smith, Crystal structure of $\mathrm{Bi}_{4} \mathrm{Ti}_{3} \mathrm{O}_{12}$, Ferroelectrics 3, 17 (1971).

${ }^{61}$ S. E. Cummings and L. E. Cross, Electrical and optical properties of ferroelectric $\mathrm{Bi}_{4} \mathrm{Ti}_{3} \mathrm{O}_{12}$ single crystals, J. Appl. Phys. 39, 2268 (1968).

${ }^{62}$ H. S. Shulman, M. Testorf, D. Damjanovic and N. Setter, Microstructure, electrical conductivity and piezoelectric properties of bismuth titanate, J. Am. Ceram. Soc. 79, 3214 (1996).
${ }^{63}$ A. Q. Jiang, H. G. Li and L. D. Zhang, Dielectric study in nanocrystalline prepared by chemical coprecipitation, J. Appl. Phys. 83, 4878 (1998).

${ }^{64} \mathrm{X}$. Du X and I. W. Chen, Ferroelectric thin films of bismuthcontaining layered perovskites: Part $\mathrm{I}, \mathrm{Bi}_{4} \mathrm{Ti}_{3} \mathrm{O}_{12}, J$. Am. Ceram. Soc. 81, 3253 (1998).

${ }^{65}$ L. B. Kong, J. Ma, W. Zhu and O. K. Tan, Preparation of $\mathrm{Bi}_{4} \mathrm{Ti}_{3} \mathrm{O}_{12}$ ceramics via a high-energy ball milling process, Mater. Lett. 51, 108 (2001).

${ }^{66}$ C. P. Shaw, S. Gupta, S. B. Stringfellow, A. Navarro, J. R. Alcock and R. W. Whatmore, Pyroelectric properties of Mn doped lead zirconate-lead titanate-lead magnesium niobate ceramics, J. Eur. Ceram. Soc. 22, 2123 (2002).

${ }^{67}$ J. G. Lisoni, P. Millán, E. Vila, J. L. Martín de Vidales, T. Hoffmann and A. Castro, Synthesis of ferroelectric Bi4Ti3O12 by alternative routes: Wet no-coprecipitation chemistry and mechanochemical activation, Chem. Mater. 13, 2084 (2001).

${ }^{68}$ B. D. Stojanovic, C. O. Paiva-Santos, C. Jovalekic, A. Z. Simoes, F. M. Filho and Z. Lazarevic, Mechanically activating formation of layered structured bismuth titanate, Mater. Chem. Phys. 96, 471 (2006).

${ }^{69}$ M. Zdujic, D. Poleti, C. Jovalekic and L. Karanovic, The evolution of structure induced by intensive milling in the system $2 \mathrm{Bi}_{2} \mathrm{O}_{3} \bullet$ $3 \mathrm{TiO}_{2}$, J. Non-Cryst. Solids 352, 3058 (2006).

${ }^{70}$ J. Hou, R. V. Kumar, Y. Qu and D. Krsmanovic, B-site doping effect on electrical properties of $\mathrm{Bi}_{4} \mathrm{Ti}_{3-2 x} \mathrm{Nb}_{x} \mathrm{Ta}_{x} \mathrm{O}_{12}$ ceramics, Scr. Mater. 61, 664 (2009).

${ }^{71}$ F. Faubert and M. Sánchez, Numerical decomposition of a complex thermostimulated depolarization current spectrum in single time relaxation peaks, J. Appl. Phys. 84, 1541 (1998). 